\title{
Evasão escolar: uma proposta de intervenção por meio de um modelo de plano estratégico de permanência e êxito
}

\author{
Maria da Graça Sousa Marinho \\ Instituto Federal do Rio Grande do Sul (IFRS) - Campus Porto Alegre \\ (gracasousa@ifma.edu.br) \\ Maria Cristina Caminha de Castilhos França \\ Instituto Federal do Rio Grande do Sul (IFRS) - Campus Porto Alegre
}

(mcristina.franca@poa.ifrs.edu.br)

\begin{abstract}
Resumo: Apesar de toda a preocupação acerca do fenômeno da evasão escolar através da bibliografia existente, o que percebemos é que ainda são altos os índices de evasão escolar na educação pública brasileira. São vários os problemas enfrentados pelas escolas brasileiras, sendo que o abandono - ao lado da repetência - ainda figura entre os maiores. Admitir a educação enquanto direito fundamental na legislação não é suficiente para que o processo educativo ocorra de forma efetiva. O país necessita de uma política educacional que possa garantir que adolescentes e jovens, independentemente da sua origem sócioeconômica, etnorracial, de gênero, dentre outras, cheguem ao fim do seu itinerário formativo. A efetivação da Educação Profissional Tecnológica (EPT) enquanto política pública, exige para a sua execução de estratégias de fortalecimento da EPT, dentre elas uma política de permanência e êxito voltada aos estudantes, só assim será possível atacar o problema da evasão que assola a educação brasileira em todos os seus níveis e modalidades. Com base no exposto, o público alvo da nossa pesquisa são os estudantes evadidos do Curso de Sistemas de Energia Renovável do Campus Santana do Livramento (IFSUL), que mantém um alto índice de evasão; e, através da pesquisa, busca-se conquistar subsídios de orientação para a elaboração de um modelo de Plano Estratégico de Permanência e Éxito dos Estudantes, com vistas a superar e combater o fenômeno da evasão e retenção no IFSul, instituição onde se dará a pesquisa. Nosso objetivo com esta pesquisa é apreender as motivações que levam os estudantes a evadirem, para tanto iremos utilizar na produção de dados questionários e entrevistas semiestruturadas, $\mathrm{O}$ referencial teórico que embasará o trabalho será de autores que pesquisam o Ensino Médio Integrado, tais como Marise Ramos e Gabriel Grabowski, bem como autores que pesquisam o fenômeno da evasão, como Rosemary Dore, Ana Zuleima Luscher e Vincent Tinto. Considera-se relevante esse estudo, tendo em vista que a evasão escolar é um tema sempre atual e que preocupa muitos profissionais na área da educação e nas instituições de ensino, utilizando como metodologia o estudo de caso e procedimentos técnicos de acordo com o método utilizado. O produto educacional resultante desta investigação será um manual orientador contendo um modelo de Plano Estratégico de Permanência e Exxito dos Estudantes que poderá ser utilizado nos Campi da Rede Federal de Ensino.
\end{abstract}

Palavras-chave: Educação Profissional Tecnológica; Ensino; Evasão Escolar; Produto Educacional.

School dropout: an intervention proposal using a model of a strategic plan for permanence and success

Abstract: Despite all the concern about the phenomenon of dropout through the existing bibliography, what we realize is that the dropout rates in Brazilian public education are still high. There are several problems faced by Brazilian schools, and dropout - alongside repetition - is still among the largest. Admitting education as a fundamental right in legislation is not enough for the educational process to take place effectively. The country needs an educational policy that can ensure that adolescents and young people, regardless of their socioeconomic, ethnoracial, gender and other origins, reach the end of their educational itinerary. The implementation of Technological Vocational Education (EFA) as a public policy requires for its implementation strategies for strengthening EFA, among them a policy of permanence and success aimed at students, only in this way it will be possible to tackle the problem of dropout that plagues education. in all its levels and modalities. Based on the above, the target audience of our research are the evaded students of the Campus Santana do Livramento Renewable 
Energy Systems Course (IFSUL), which maintains a high dropout rate; and, through the research, it seeks to obtain orientation subsidies for the elaboration of a model of Strategic Plan of Permanence and Success of Students, with a view to overcoming and combating the phenomenon of dropout and retention in IFSul, institution where the research will take place. . Our goal with this research is to grasp the motivations that lead students to evade, so we will use in the production of questionnaires and semi-structured interviews. The theoretical framework that will support the work will be from authors who research the Integrated High School, such as Marise Ramos. and Gabriel Grabowski, as well as authors researching the phenomenon of dropout, such as Rosemary Dore, Ana Zuleima Luscher and Vincent Tinto. This study is considered relevant, considering that school dropout is an always current theme and that concerns many professionals in the area of education and educational institutions, using as a methodology the case study and technical procedures according to the method used. . The educational product resulting from this research will be a guiding manual containing a model of Strategic Plan of Permanence and Success of Students that can be used in Federal Education Campuses.

Keywords: Technological Professional Education; Teaching; School Dropout; Educational Product.

\section{INTRODUÇÃO}

O Instituto Federal de Educação, Ciência e Tecnologia Sul-riograndense (IFSul), é uma instituição que integra a Rede Federal de Educação Profissional e Tecnológica, tendo sido criada a partir do Centro Federal de Educação Tecnológica (CEFET)-RS, nos termos da Lei n¹1.892, de 29 de dezembro de 2008. O IFSul é composto de quatorze campi: Bagé, Camaquã, Charqueadas, Gravataí, Jaguarão, Lajeado, Novo Hamburgo, Passo Fundo, Pelotas, Pelotas-Visconde da Graça, Santana do Livramento, Sapucaia do Sul, Sapiranga e Venâncio Aires.

O IFSul, em consonância com os outros Institutos Federais, tem como características a verticalização do ensino, a oferta de educação profissional e tecnológica em diferentes níveis e modalidades de ensino, articulando a educação básica, superior e tecnológica. De acordo com o PDI (2014-2019) outro papel que o IFSul vem desempenhando é o de

produtor de conhecimentos científicos e tecnológicos, assim como disseminador da práticas culturais, o Instituto está sendo desafiado a estabelecer relações de parcerias que ampliem e qualifiquem o fluxo de conhecimento e práticas de interesse regional (...) as demandas sociais com as quais o IFSul se depara impõem um diálogo permanente com a comunidade refletindo-se no seu dia-a-dia, exigindo a democratização da produção e a difusão do conhecimento" (PDI, 2014, pág. 21).

O Campus Santana do Livramento do IFSul, local onde está sendo desenvolvida a pesquisa, está situado na fronteira entre o Brasil e o Uruguai. A fronteira é constituída pelas cidades de Santana do Livramento (Brasil) e Rivera 
(Uruguai), e é um dos seis pares de cidades fronteiriças localizados entre os 1003 $\mathrm{km}$ que conformam a fronteira entre Brasil e Uruguai.

É formada sobre linha imaginária, sem nenhum acidente geográfico que separe as duas cidades, chamadas de cidades gêmeas. Sua originalidade é marcada, por ter um peso demográfico similar, e pertencer a unidades políticas também comparáveis (município e departamento), não sendo evidente um domínio de nenhuma das duas cidades sobre a outra, podendo atravessar o limite imaginário livremente, sem necessidade de controle de aduanas.

Em 2009 tem início a história de formação do Campus Santana do Livramento estabelecida entre o Instituto Federal Sul-rio-grandense (IFSul) e o Conselho de Educação Técnico Profissional da Universidade do Trabalho do Uruguai (CETP-UTU). A parceria foi oficialmente estabelecida, em reunião realizada na cidade de Montevidéu - Uruguai com a Agência Brasileira de Cooperação (ABC), órgão vinculado ao Ministério das Relações Exteriores do Brasil. Essa parceria tem como fundamento os seguintes documentos: Acordo Básico de Cooperação Econômica, Científica e Técnica, firmado através do Decreto Legislativo $n^{\circ} 67$ de 12 de junho de 1975; Acordo sobre Permissão de Residência, Estudo e Trabalho a Nacionais Fronteiriços Uruguaios e Brasileiros, subscrito em 21 de agosto de 2002 e promulgado pelo Decreto Legislativo nº 907 de 21/11/2003; Acordo para criação de Escolas e/ou Institutos Binacionais Fronteiriços Profissionais e/ou Técnicos e para a Habilitação de Cursos Técnicos Binacionais Fronteiriços, conforme Decreto Presidencial $n^{\circ} 8455$ de 20/05/2015.

Ainda em 2009, os projetos pedagógicos dos cursos binacionais foram construídos em conjunto pelas instituições parceiras, com aprovação nos conselhos superiores, a fim de viabilizar o reconhecimento automático dos diplomas nos países envolvidos. No ano seguinte, começou-se a efetivar a implantação do Campus Avançado Santana do Livramento com o início das atividades do Campus através da oferta dos Cursos Técnicos Binacionais nas áreas de indústria, energia e meio ambiente.

O Campus Santana do Livramento está localizado junto ao limite entre os dois países, na rua localizada do lado brasileiro da fronteira, lugar este localmente chamado Línea e os estudantes provêm de ambos os lados da fronteira. Os estudantes brasileiros ingressam na instituição escolar pelo vestibular e os alunos 
uruguaios são admitidos por sorteio, realizado na escola irmã do lado uruguaio, UTU (Universidade do Trabalho do Uruguai).

O artigo tem como objetivo geral identificar as motivações que levam os estudantes a evasão do Curso Técnico Integrado em Sistemas de Energia Renovável do Instituto Federal de Educação, Ciência e Tecnologia Sul-riograndense (IFSul) - Campus Santana do Livramento. Partindo desse pressuposto, nossa intenção será percorrer os caminhos para apreender, primeiramente, de que forma tem se apresentado o fenômeno da evasão escolar no Brasil, mais especificamente na Rede Federal de Educação Profissional e Tecnológica, com recorte no IFSul; em seguida, iremos apresentar os objetivos e o caminho metodológico a ser percorrido ao longo de toda pesquisa. O passo seguinte, será apresentar a teoria norteadora do presente trabalho, através das bases conceituais que irão fundamentar a pesquisa; e, por fim, e não menos importante, apresentaremos a proposta de resultados da pesquisa que será a elaboração de um modelo de plano estratégico de permanência e êxito dos estudantes.

A relevância acadêmica do projeto mostra-se interessante já que o estudo com estudantes brasileiros e uruguaios, em uma escola binacional, traz elementos para discussão sobre as vivências e dificuldades enfrentadas por esses estudantes, considerando as diferenças sobre as políticas públicas que envolvem a Educação Profissional e Tecnológica, bem como legislações que regulam a EPT diferenciadas.

Para os próprios estudantes, torna-se relevante não só pela oportunidade de sentir que suas necessidades são ouvidas pela instituição, bem como, perceber, devido ao mecanismo de identificação grupal, que alguns sentimentos e expectativas também são vivenciados pelos outros membros do grupo, diminuindo assim, a sensação de isolamento. Podemos apontar como questionamentos da investigação: quais são as estratégias possíveis de contribuição da instituição para a permanência dos estudantes no curso de Sistemas de Energia Renovável? Tendo como problema central, quais são os fatores que levam os estudantes à evasão/permanência e quais estão diretamente ligados à instituição?

O fenômeno da evasão no Brasil é um problema real, mas a pouca bibliografia torna o tema desafiador e instigante, 
significa o acesso dos estudantes à escola e a sua permanência nos estudos, a crise em um desses dois termos se mostra um problema. A evasão se refere justamente aos fatores que levam o estudante a não permanecer nos estudos. É, portanto, uma questão relacionada à democratização da escola técnica no país (MACHADO; MOREIRA, 2009, p. 3).

Dore e Lüscher reforçam essa questão quando afirmam que

a pesquisa sobre evasão escolar no ensino técnico no Brasil encontra um de seus maiores problemas e um grande desafio na escassez de informações sobre o assunto. A falta de informações abrange tanto o referencial teórico quanto o empírico e cria dificuldades adicionais à pesquisa para construção de indicadores adequados à investigação do problema. (DORE; LÜSCHER, 2011, p. 782)

De acordo com Pelissari "o conceito de evasão traz um caráter subjetivista, responsabilizando o aluno pela sua saída da escola, considerando apenas os fatores externos, caindo na armadilha do reprodutivismo das relações sociais na escola". (PELISSARI, 2012, p.33)

Apesar de toda a preocupação acerca do fenômeno da evasão escolar através da bibliografia existente, o que percebemos é que ainda são altos os índices de evasão escolar na educação pública brasileira. São vários os problemas enfrentados pelas escolas brasileiras, sendo que o abandono ao lado da repetência ainda figura entre os maiores. Tendo em vista que a Educação é definida pela Constituição Federal de 1988 enquanto um direito social, a letra da lei afirma ainda ser direito de todos, devendo ser promovida de forma a garantir a promoção do pleno desenvolvimento da pessoa, no preparo para o exercício da cidadania e na qualificação para o trabalho.

A Rede Federal de Educação Profissional e Tecnológica tem se feito presente no Brasil por mais de 100 anos, contribuindo no processo de acesso ao ensino médio técnico de adolescentes e jovens. A história da Educação Profissional e Tecnológica tem mostrado que a preocupação com essa modalidade de ensino começou em 1909, através da criação das escolas de aprendizes e artífices que ofertava educação destinada "às classes menos favorecidas", cujos pessoas também eram chamados de "desafortunadas". Essa medida tinha como principal objetivo a geração de mão de obra ao sistema capitalista. Nesse contexto está o nascedouro da educação profissional do país. 
Com o passar das décadas houve a mudança das nomenclaturas dessas escolas para Escolas Técnicas, depois Centros Federais de Educação Tecnológica, mas houve também mudança nas teorias da educação, nas concepções pedagógicas, bem como do público alvo atendidos por essas instituições.

Mas, o grande marco de mudança para a concepção de uma identidade única de educação profissional e tecnológica se deu em 2008, quando da criação dos Institutos Federais de Educação, Ciência e Tecnologia, através da Lei nº 11.892 de 29 de dezembro do referido ano. Os Institutos Federais são a conjugação de instituições como: os Centros Federais de Educação Tecnológica (CEFETs), Escolas Agrotécnicas, Escolas Técnicas Federais e parte das escolas vinculadas às universidades (BRASIL, 2010).

A rede federal continua ofertando cursos técnicos de nível médio, mas passou a ofertar também cursos de graduação e pós-graduação. Atualmente são 38 Institutos Federais, a Universidade Tecnológica Federal do Paraná (UTFPR), 2 Centros Federais de Educação Tecnológica (Cefet), 23 escolas técnicas vinculadas as universidades federais e o Colégio Pedro II. Essas instituições compreendem um universo de 643 campi presentes em 568 municípios ao longo de toda extensão territorial brasileira, ofertando ensino público, gratuito e de qualidade.

A educação profissional tecnológica deve estar além da preparação para o mercado de trabalho, não pode ser vista apenas como instrumento de qualificação de mão de obra para as relações de produção capitalistas. Precisa sim, ser vista como uma política pública e não apenas como uma modalidade de ensino, devendo ser articulada à educação básica, para tanto, torna-se necessário

construir, com toda a sociedade, uma proposta de política pública de educação profissional e tecnológica, embasada numa concepção de mundo, homem e sociedade como sujeitos e não como objetos do mercado capitalista e voltada para um projeto de nação soberana e independente é desafio que não pode ser postergado" (GRABOWSKI, 2010, p. 279).

Grabowski (2010) vai mais além, afirma que

urge conceber a educação profissional, na perspectiva estratégica de política, como fator de inclusão social, de desenvolvimento econômico, de geração de trabalho e renda, dentre outras dimensões de natureza pedagógica, social e epistemológica. Neste último campo, o epistemológico, trata-se de construção de conhecimento como trabalho não meramente técnico, mas científico e cultural. Na social, a estratégia política realça as relações conflituosas que são responsáveis pela produção e apropriação dos conhecimentos. $\mathrm{Na}$ dimensão pedagógica, objetiva formar e educar cidadãos e 
profissionais com autonomia ética, política, intelectual e tecnológica. (GRABOWSKI, 2010, p. 279)

Apesar do crescente aumento das vagas na rede federal a partir da sua expansão, muitos problemas ainda são enfrentados pelas instituições que compõem a rede federal, tais como: os problemas de ordem financeira, de ensino-aprendizagem, de infraestrutura, de currículo. Contudo, o problema que tem sido alvo de discussões e carece de pesquisas voltadas à intervenção é o fenômeno da evasão escolar. Dore e Lüscher (2011) afirmam que a evasão escolar

tem sido associada a situações tão diversas quanto a retenção e repetência do aluno na escola, a saída do aluno da instituição, a saída do aluno do sistema de ensino, a não conclusão de um determinado nível de ensino, o abandono da escola e posterior retorno. Refere-se ainda àqueles indivíduos que nunca ingressaram em um determinado nível de ensino, especialmente na educação compulsória, e ao estudante que concluiu um determinado nível de ensino, mas se comporta como um dropout (abandono) (DORE e LÜSCHER, 2011, p.775)

Em relação ao sucesso escolar, tanto a CF/1988 quanto a Lei de Diretrizes e Bases da Educação (LDB), Lei nº 9.394 de 1996, indicam princípios como: igualdade de condições para o acesso e permanência na escola, garantia do padrão de qualidade, a valorização do profissional da educação escolar e a vinculação entre a educação escolar e as práticas sociais. Admitir a educação enquanto direito fundamental na legislação não é suficiente para que o processo educativo ocorra de forma efetiva. Com isso, torna-se urgente lutar por ações que permitam a concretização desse direito e sugere-se uma educação "como processo que, emergindo do social, a ele deve retornar, num processo de trabalho comunitário, participativo; uma alternativa capaz de levantar a escola da falência onde se encontra" (VIANNA, 2000, p.63).

A educação profissional é apresentada pela legislação brasileira, mais precisamente pela LDB/96, como modalidade educacional que se integra aos diferentes níveis e etapas de educação, as dimensões do trabalho, da ciência e da tecnologia, com a finalidade principal de preparar para o exercício de profissões, contribuindo para que o cidadão possa se inserir e atuar no mundo do trabalho e na vida em sociedade.

Parece provável que, para a efetivação da Educação Profissional Tecnológica (EPT) enquanto política pública, torna-se mister a execução de estratégias de 
fortalecimento da EPT, dentre elas nos parece que uma política de permanência e êxito voltada aos estudantes é de extrema relevância e urgência, para atacar um problema sério que assola a educação brasileira em todos os seus níveis e modalidades. Como nos ensina Ramos (2010), o fenômeno da evasão escolar deve ser colocado no topo das pautas educacionais, uma vez que "a negação da escolarização não significa a exclusão do acesso dos jovens à escola, mas uma exclusão que, no seu próprio interior, promove a perda da função social da escola de promover a formação dos seus educandos" (RAMOS, 2010, p. 98).

A educação profissional tecnológica tem evoluído muito quando o assunto é o acesso, mas muito ainda há de ser feito para que os nossos adolescentes e jovens tenham garantido seu direito constitucional de escolarização, necessário se faz que seja garantido não apenas a universalização do acesso a um ensino gratuito e de qualidade, mas principalmente condições reais de permanência e êxito.

Segundo Fritsch a evasão:

É um fenômeno complexo, associado com a não concretização de expectativas e reflexo de múltiplas causas que precisam ser compreendidas no contexto socioeconômico, político e cultural, no sistema educacional e nas instituições de ensino. Caracteriza-se por ser um processo de exclusão determinado por fatores e variáveis internas e externas às instituições de ensino. No campo da gestão educacional, a evasão é um indicador de fluxo escolar que sinaliza, de alguma forma, o desempenho dos sistemas de ensino. Esse processo é percebido tanto em instituições de âmbito público quanto privado (FRITSCH, 2015, p. 2).

Sobre abandono da escola Batista, Souza e Oliveira (2009, p. 4) afirmam que é composto então pela conjugação de várias dimensões que interagem e se conflitam no interior dessa problemática. Dimensões estas de ordem política, econômica, cultural e de caráter social. Dessa maneira, o abandono escolar não pode ser compreendido, analisado de forma isolada. Isto porque, as dimensões socioeconômicas, culturais, educacionais, históricas e sociais entre outras, influenciam na decisão tomada pela pessoa em abandonar a escola (BATISTA; SOUZA; OLIVEIRA, 2009, p.4).

Ainda sobre o termo Abandono Tinto conceituou como sendo "o resultado de um processo multidimensional envolvendo a interação entre o indivíduo e a instituição, não é de surpreender que as características da instituição, mesmo no nível agregado, também tenham se mostrado relacionadas a taxas diferenciais de abandono". (TINTO, 1975, p. 13)

Ferreira (2016) aborda a temática a partir da concepção de fracasso. Afirma que fracasso escolar 
é um assunto bem conhecido e há inúmeras discussões sobre o ensino, abordando a realidade a ser encarada. Contudo, apesar desse fato existir nas escolas, o desafio não está só na abordagem e na discussão, mas nas análises superficiais e generalizadas que ligam fracasso como algo externo ao processo de ensino. (FERREIRA, 2016, p. 129)

Ainda a mesma autora vai conceituar o termo "fracasso" como, "desgraça; desastre; ruína; perda; mau êxito; malogro. Assim, fracasso escolar é um mau êxito na escola, (...) uma reprovação, ou evasão escolar, e pode-se considerar, também, aprovação com baixo índice na aprendizagem" (FERREIRA, 2016, p. 130).

Neste trabalho, iremos trabalhar com o termo evasão entendendo este como um fenômeno que abrange e culmina no fracasso e abandono escolar. Outras situações que contribuem para a evasão escolar são a retenção e repetência dos estudantes. Considerando evasão escolar o fenômeno onde os estudantes possuem matrícula e frequentaram a Instituição de ensino por um período ou ciclo e depois deixaram de comparecer à escola, sem fornecer uma explicação para a unidade de ensino.

Além da definição de um conceito, outras questões somam a complexidade de se entender o fenômeno da evasão, como as suas causas, sobre isso Dore e Lüscher (2011) afirmam que

as possíveis causas da evasão são extremamente difíceis de serem identificadas porque, de forma análoga a outros processos vinculados ao desempenho escolar, a evasão é influenciada por um conjunto de fatores que se relacionam tanto ao estudante e à sua família quanto à escola e à comunidade que vive (DORE; LÜSCHER, 2011, p. 5)

Tendo em vista, que o público alvo da nossa pesquisa são os estudantes evadidos do Curso de Sistemas de Energia Renovável do Campus Santana do Livramento (IFSUL), e que a faixa etária desse público está entre 15 anos a 18 anos.

É importante ter a apreensão das mudanças das fases da vida, a saber da infância para a adolescência, da adolescência para a juventude e desta para a adulta, pois somente a partir da compreensão do processo como um todo, será possível compreender que as fases que englobam a adolescência e a juventude são bem mais complexas que um simples rito de passagem.

Para Dayrell e Carrano a juventude

é, ao mesmo tempo, uma condição social e um tipo de representação. De um lado há um caráter universal, dado pelas transformações do indivíduo numa determinada faixa etária. De outro, há diferentes construções históricas e sociais relacionadas a esse tempo/ciclo da 
vida. A entrada na juventude se faz pela fase da adolescência e é marcada por transformações biológicas, psicológicas e de inserção social. É nessa fase que fisicamente se adquire o poder de gerar filhos, em que a pessoa dá sinais de ter necessidade de menos proteção por parte da família e começa a assumir responsabilidades, a buscar a independência e a dar provas de autossuficiência, dentre outros sinais corporais, psicológicos e de autonomização cultural (DAYRELL E CARRANO, 2014, p. 111).

A escola tem papel fundamental nesse processo de formação humana dos nossos adolescentes/jovens, por isso torna-se necessário conhecer esses estudantes que frequentam as escolas, buscando as informações, bem como os

dados específicos que podem ampliar o nosso conhecimento e a compreensão da realidade. É por meio dessa compreensão que poderemos reorientar nossas imagens, visões e formas de lidar com os jovens estudantes com os quais convivemos. Daí a importância de conhecer algumas dimensões que consideramos fundamentais da condição juvenil no Brasil, esperando que sirvam de possíveis chaves de análise para aprofundar a compreensão em torno das juventudes. (DAYRELL e CARRANO, 2014, p. 115).

Por essa razão é tão importante que seja fortalecida no país uma política educacional que garanta não apenas o acesso, mas se faz primordial a garantia também da permanência e da conclusão dos estudantes. É essa política que irá fazer com que adolescentes e jovens, independentemente da sua origem sócioeconômica, etnorracial, de gênero, dentre outras, cheguem ao fim do seu itinerário formativo. Esse itinerário deve prever a garantia de que sejam desenvolvidas habilidades para sua inserção na sociedade de forma digna e cidadã, que tenha a opção de adentrar no mundo do trabalho, bem como dar continuidade aos estudos em nível superior.

O artigo tem como objetivo geral analisar as motivações da evasão/permanência dos estudantes brasileiros e uruguaios no curso técnico integrado Sistemas de Energia Renovável do Instituto Federal Sul-Rio-Grandense Campus Santana do Livramento e como objetivos específicos, identificar os possíveis fatores que levam os estudantes a evasão/permanência, definir metas que minimizem o processo de evasão dos estudantes, conforme as dimensões apontadas nos dados da pesquisa, criar um produto educacional e avaliar a contribuição desse produto enquanto instrumento orientador junto aos diferentes segmentos institucionais. 


\section{MATERIAIS E MÉTODOS}

Considerando o objetivo da pesquisa ser a verificação dos fatores motivacionais que levam os estudantes a evadir e abandonar a escolar, assim como identificar o quantitativo dos estudantes evadidos no Curso de Sistemas de Energia Renovável do Campus Santana do Livramento/IFSul, a pesquisa será de abordagem será de natureza qualitativa.

A produção de dados adotará o método estudo de casos, sendo a coleta de dados através da aplicação de questionários com os estudantes brasileiros e uruguaios que estão cursando e entrevistas com estudantes que evadiram do curso; faremos entrevista semiestruturada com o coordenador do curso do campus para investigar possíveis fatores que possam ter contribuído com a não continuidade dos estudantes na Instituição. Outros interlocutores serão os membros da família dos estudantes evadidos que, por meio de questões em entrevistas mais abertas, tentaremos entender possíveis razões externas ao Campus que possam ter favorecido a evasão dos estudantes, bem como possíveis fatores de proteção, para que sejam alcançados a permanência e o sucesso na trajetória acadêmica.

Tendo já conseguido a autorização do Diretor Geral do Campus para realização de pesquisas com estudantes e servidores dentro da instituição, partiremos para a coleta de dados. Também será entregue um Termo de Assentimento Livre e Esclarecido aos estudantes menores de idade, bem como um Termo de Consentimento Livre e Esclarecido, solicitando aos pais e/ou responsáveis dos estudantes menores de idade e aos interlocutores da própria instituição o preenchimento do Termo de Consentimento para participar da pesquisa.

\section{RESULTADOS}

Após detectar as causas da evasão no curso de Sistemas de Energia Renovável do IFSUL - Campus Santana do Livramento através da execução da pesquisa, o presente projeto apresentará como proposta de resultados a elaboração 
de um modelo de Plano Estratégico de Permanência dos Estudantes e Êxito que sirva de instrumento orientador sobre o curso, onde os estudantes poderão dirimir as suas dúvidas e anseios acerca do mesmo, bem como as possibilidades externas e internas à Instituição. A proposta da construção de um modelo de Plano Estratégico de Permanência dos Estudantes deve fazer parte da política de permanência e êxito dos estudantes, principalmente daqueles que se encontram em situação de vulnerabilidade social, na perspectiva da equidade, da produção de conhecimento, da melhoria do desempenho acadêmico e da qualidade de vida. Para alcançar tais objetivos já realizamos a coleta dos dados, por meio de aplicação de questionários e entrevistas. Com a coleta dos registros realizada, nos encontramos no momento na fase da organização e análise dos dados.

\section{DISCUSSÃO}

Esse fenômeno tem se configurado como um dos gargalos das instituições de ensino, principalmente, das instituições públicas em todos os níveis e modalidades de ensino, como mostram as estratégias das instituições em tentar frear esse problema, temos constatado isso tantos nas pesquisas, como nos estudos e estratégias das instituições públicas e privadas do país.

Posto isso, torna-se importante destacar que o problema da evasão escolar não se configura enquanto um problema de ordem meramente acadêmica, mas também, um problema interno da instituição. Nessa direção, concordamos com Batista, Souza e Oliveira (2009) quando esclarecem que

a evasão escolar não é um problema restrito aos muros intraescolares, uma vez que reflete as profundas desigualdades sociais existentes em nosso país e se constitui como um problema social. A situação é alarmante, principalmente por se tratar de uma parcela jovem da população que está excluída dos bens culturais da sociedade. Além disso, encontra-se fora do mercado de trabalho, por não atender às exigências da sociedade hodierna, cada vez mais integrada à globalização e aos ditames do projeto neoliberal no que diz respeito à qualificação da mão-de-obra (BATISTA; SOUZA; OLIVEIRA, 2009, p. $6)$.

Em 2014 os índices de evasão escolar nos Institutos Federais chegaram em pontos tão alarmantes que foi necessário uma intervenção do Tribunal de Contas da União que elaborou um diagnóstico, resultado de uma auditoria apontando os 
principais pontos a serem atacados para frear o alto índice de evasão nos institutos. Dessa auditoria nasceu um documento orientador, recomendando ao Ministério da Educação (MEC) a elaboração de planos de combate e prevenção à evasão. O plano de ação composto por sete diretrizes norteadoras que abrangem o entendimento dos fenômenos da evasão e retenção na Rede Federal e medidas para o seu combate, tais como: a formação de parcerias, o desenvolvimento da pesquisa e inovação, a inserção profissional dos estudantes, a distribuição de cargos e funções às instituições, a capacitação dos servidores e a avaliação de cursos de educação profissional e tecnológica. (MEC, 2014, p. 7).

Para a elaboração do documento orientador foi realizado um amplo debate com atores dos Institutos Federais, sendo resultado de um processo coletivo de discussões em que

as instituições foram instadas a realizar diagnósticos locais sobre a evasão e retenção em cursos técnicos e de graduação, com indicação de causas e medidas de combate, e a participar, por meio do envolvimento direto de representantes, de uma oficina para consolidar uma proposta para o plano estratégico de intervenção e monitoramento para superação da evasão e retenção. Apesar da análise ter se pautado nos cursos técnicos de nível médio e nos cursos de graduação ofertados na modalidade presencial, as orientações apresentadas a seguir devem ser aplicadas a todas as ofertas educacionais das instituições integrantes da Rede Federal de Educação Profissional e Tecnológica. (MEC, 2014, p.7)

A partir das indicações dispostas no documento orientador para a superação da evasão e retenção na rede federal de educação profissional, cientifica e tecnológica cada Instituto Federal recebeu a incumbência de elaborar seu Plano Estratégico de Intervenção e Monitoramento com vistas a superar e combater o fenômeno da evasão e retenção em suas instituições e respectivos campus. O documento orientador ainda aponta os atores que devem ser envolvidos no processo de elaboração e execução do plano estratégico que são: gestores sistêmicos de ensino e de assistência estudantil, coordenadores de curso e equipe técnico pedagógica, bem como outros profissionais que se interessem pela temática. Nessa direção, o diagnóstico aponta que existe a necessidade de pesquisar e avaliar se todos os 38 Institutos Federais elaboraram seus planos, e mais do que isso, se os objetivos traçados estão sendo alcançados, se está havendo de fato um trabalho de combate, superação e prevenção da evasão escolar que garanta o desenvolvimento 
de ações capazes de ampliar as possibilidades de permanência e êxito dos estudantes na educação profissional e tecnológica.

Desse modo, os estudos desenvolvidos no mestrado visam, de forma pontual, elaborar um modelo de Plano Estratégico de Permanência dos Estudantes, considerando as narrativas de estudantes e egressos de um curso do IFSUL, Campus Santana do Livramento, que compreende um número bastante elevado de evasão e retenção de estudantes. Outros interlocutores, considerados fundamentais para o tema em questão, também participarão da pesquisa, de modo a compor as diferentes dimensões implicadas no processo que atinge negativamente a educação no Brasil.

\section{CONSIDERAÇÕES FINAIS}

O fenômeno da evasão tem se configurado como um dos gargalos das instituições de ensino, principalmente, das instituições públicas em todos os níveis e modalidades de ensino, como mostram as estratégias das instituições em tentar frear esse problema, temos constatado isso tantos nas pesquisas, como nos estudos e estratégias das instituições públicas e privadas do país.

Posto isso, torna-se importante destacar que o problema da evasão escolar não se configura enquanto um problema de ordem meramente acadêmica, mas também, um problema interno da instituição.

A pesquisa sobre o fenômeno da evasão irá configurar enquanto um importante instrumento de reflexão no âmbito do Campus Santana do Livramento, uma vez que discutir evasão/permanência dos estudantes implicará na análise do próprio desenvolvimento da instituição no contexto da expansão de Rede Federal de Educação Profissional e Tecnológica. Nessa direção, pretende-se analisar os impactos da evasão para a oferta do curso de sistemas de energias renovável na instituição, o que irá possibilitar o planejamento de estratégias que promovam a sua superação. Problematizar a evasão significa, antes de tudo, rejeitar a ideia da evasão enquanto condição intrínseca da instituição, não cabe o papel de mera reprodutora das mazelas sociais, mas sim deve ser um local no qual se deve exaltar e mobilizar as potencialidades criativas e transformadoras. A superação do estigma da evasão associado à escola pública brasileira é um desafio imperativo para alicerçar o ideal de educação pública, democrática e de qualidade. 
Desse modo, os estudos desenvolvidos pela pesquisa visam, de forma pontual, elaborar um modelo de Plano Estratégico de Permanência dos Estudantes, considerando as narrativas de estudantes e egressos de um curso do IFSUL, Campus Santana do Livramento, que compreende um número bastante elevado de evasão e retenção de estudantes. Outros interlocutores, considerados fundamentais para o tema em questão, também participarão da pesquisa, de modo a compor as diferentes dimensões implicadas no processo que atinge negativamente a educação no Brasil. O objetivo principal da pesquisa é a elaboração de um modelo de Plano Estratégico de Permanência e Êxito dos estudantes dos cursos técnicos da Rede Federal de Educação que contribua para, se não uma solução ao fenômeno da evasão, pelo menos, uma estratégia de intervenção que contribua para que os estudantes se mantenham na instituição e consigam chegar ao fim do seu percurso educativo; ou seja, chegarem a conclusão do curso.

A proposta da construção de um modelo de Plano Estratégico de Permanência dos Estudantes deve fazer parte da política de permanência e êxito dos estudantes, principalmente daqueles que se encontram em situação de vulnerabilidade social, na perspectiva da equidade, da produção de conhecimento, da melhoria do desempenho acadêmico e da qualidade de vida. Assim, estaremos contribuindo no processo de ensino e de aprendizagem no âmbito da Rede Federal de Educação.

\section{REFERÊNCIAS}

BATISTA, Santos Dias, SOUZA, Alexsandra Matos, OLIVEIRA, Júlia Maria da Silva. A Evasão Escolar no Ensino Médio: Um estudo de caso. Revista Profissão Docente, Uberaba, v.9, n.19, 2009. Disponível em: <www.uniube.br/propep/mestrado/revista>. Acesso em 12 de maio de 2019.

BRASIL. Constituição (1988). Constituição da Repúbllica Federativa do Brasil: promulgada em 05 de outubro de 1988. Disponivel em < www.planalto.gov.br>. Acesso em: 28 de maio de 2019.

. Lei n 9394, de 20 de dezembro de 1996. Estabelece as diretrizes e

bases da educação nacional. Disponível em <www.planalto.gov.br.>. Acesso em: 30 de maio de 2019. 
Ministério da Educação. Documento Orientador para a Superação da Evasão e Retenção na Rede federal de Educação Profissional, Científica e Tecnológica. Secretaria de Educação Profissional e Tecnológica. 2014.

. Ministério da Educação. Documento Orientador para a Superação da Evasão e Retenção na Rede federal de Educação Profissional, Científica e Tecnológica. Secretaria de Educação Profissional e Tecnológica. 2014.

DAYRELL, Juarez, CARRANO, Paulo, MAIA, C. Linhares. (org.). Juventude e Ensino Médio: sujeitos e currículos em diálogo. DAYRELL, Juarez e CARRANO, Paulo. Juventude e Ensino Médio: quem é este aluno que chega à escola. Belo Horizonte. Editora UFMG. 2014, p. 101 a 133.

DORE, Rosemary, LÜSCHER, Ana Zuleima. Permanência e Evasão na Educação Técnica de Nível Médio em Minas Gerais. Cadernos de Pesquisa, São Paulo, v. 41, n. 144, 2011. Disponível em <http://publicacoes.fcc.org.br/ojs/index.php>. Acesso em 10 de maio de 2019.

FERREIRA, Claudia Maria Silva. Fracasso Escolar. Revista Facfama. v. 5, n. 3 , 2016. Disponível em <http://revista.facfama.edu.br/index.php/ROS/article/view/198/156>. Acesso em: 10/04/2019.

FRITSCH,R. (2015) A problemática da evasão em cursos de graduação em uma universidade privada. Anais $37^{a}$ Reunião Nacional da ANPED. Florianópolis: UFSC. Disponível em http://www.anped.org.br/biblioteca/item/problematicadaevasaoemcursosdegraduacao emumauniver->. Acesso em 01/04/2019.

MOLL, Jaqueline (org.). Educação profissional e tecnológica no brasil contemporaneo: desafios, tensões e possibilidades. Marise Ramos. Ensino Médio Integrado: ciência, trabalho e cultura na relação entre educação profissional e educação básica. Editora Artmed, Porto Alegre, 2010. p. 42-57.

. Educação profissional e tecnológica no brasil contemporaneo: desafios, tensões e possibilidades. Gabriel Grabowski. Reforma, legislação e financiamento da educação profissional no Brasil. 2010. p. 271-284.

RIFFEL, S.Marmol, MALACARNE, Vilmar. Evasão Escolar no ensino médio: o caso do Colégio Estadual Santo Agostinho no município de Palotina, 2010. Disponível em < http://www.diaadiaeducacao.pr.gov.br/portals/pde/arquivos/19968.pdf>. Acesso em 17/05/2019.

VIANNA, Ilca Oliveira. Planejamento Participativo na escola: um desafio ao educador, editora Pedagógica e universitária. 2 edição, São Paulo, 2000.

TINTO, Vincent. Abandono do ensino superior: uma síntese teórica de pesquisas recentes. Revisão de pesquisa educacional, Washington, v. 45, n.1, p.89-125, 1975. 